\title{
High expression of FUSE binding protein 1 in breast cancer stimulates cell proliferation and diminishes drug sensitivity
}

\author{
WEI LIU ${ }^{1,2^{*}}$, XIFENG XIONG ${ }^{3 *}$, WEIGUANG CHEN ${ }^{1}$, XIAOJIAN LI $^{2}$, \\ XING HUA ${ }^{4}$, ZHIHE LIU $^{3}$ and ZHI ZHANG ${ }^{2}$ \\ Departments of ${ }^{1}$ Breast Surgery, ${ }^{2}$ Burns and Plastic Surgery, ${ }^{3}$ Guangzhou Institute of Traumatic Surgery, and \\ ${ }^{4}$ Pathology, Guangzhou Red Cross Hospital, Jinan University, Guangzhou, Guangdong 510220, P.R. China
}

Received December 10, 2019; Accepted May 29, 2020

DOI: $10.3892 /$ ijo.2020.5080

\begin{abstract}
Breast cancer is the most common malignant tumor affecting women worldwide and is divided into the following subtypes: Luminal A, Luminal B, HER-2 overexpression and triple-negative breast cancer (TNBC). TNBC accounts for approximately $15-20 \%$ of all breast cancer cases. Due to the characteristics of low differentiation, the likelyhood of recurrence and metastasis, strong invasiveness and the lack of hormone receptors and human epidermal growth factor receptor 2 (HER2), patients with TNBC cannot benefit from endocrine therapy or other available targeted agents. Chemotherapy is one of the main treatments for patients with TNBC, and cisplatin is one of the most commonly used and effective drugs. The human far upstream element binding protein 1 (FBP1) is a potent pro-proliferative and anti-apoptotic oncoprotein, which is overexpressed in numerous tumor types. The present study demonstrated that FBP1 and its target, c-Myc, were more highly expressed in breast cancer tissues compared with para-carcinoma tissues, and the FBP1 and c-Myc levels are decreased by cisplatin treatment. The knockdown of FBP1 in TNBC cells decreased cell proliferation by arresting the cell cycle at the G2 phase. The knockdown of FBP1 decreased the expression of $\mathrm{G} 2$ phase-associateed protein cyclin A2, whereas it increased that of cyclin B1 and p-CDC2. Furthermore, the knockdown of FBP1 decreased cell migration and metastasis
\end{abstract}

Correspondence to: Dr Zhi Zhang, Department of Burns and Plastic Surgery, Guangzhou Red Cross Hospital, Jinan University, 396 Tongfu Zhong Road, Guangzhou, Guangdong 510220, P.R. China

E-mail: zhangzhicc48@163.com

Dr Zhihe Liu, Guangzhou Institute of Traumatic Surgery, Guangzhou Red Cross Hospital, Jinan University, 396 Tongfu Zhong Road, Guangzhou, Guangdong 510220, P.R. China

E-mail: zliu0731@163.com

*Contributed equally

Key words: binding protein 1, cell proliferation, cell migration and metastasis, drug sensitivity by downregulating matrix metalloproteinase 2 expression, and enhanced the sensitivity of TNBC cells to cisplatin by inducing apoptosis. These results thus suggest that FBP1 is a potential novel biological marker for the diagnosis and treatment of TNBC.

\section{Introduction}

Breast cancer is the most common malignant tumor affecting women worldwide (1). According to the expression of estrogen receptor (ER), progesterone receptor (PR), human epidermal growth factor receptor 2 (HER-2) and Ki-67 in breast cancer cells, breast cancer is divided into Luminal A, Luminal B, HER-2-overexpressing and triple-negative breast cancer (TNBC) subtypes (2). TNBC, which is ER-, PR- and HER-2-negative, accounts for 15-20\% of breast cancer cases. TNBC is characterized by a low differentiation, strong invasiveness, an increased likelihood of recurrence and metastasis, and a poor prognosis $(3,4)$. Due to the lack of hormone receptor and HER-2 expression, patients with TNBC cannot benefit from endocrine therapy or other available targeted agents. Therefore, the understanding of the underlying molecular mechanisms of TNBC is crucial in order to be able to identify novel therapeutic targets.

Platinum-based drugs are used extensively in the treatment of malignant tumors. Carboplatin can reduce the expression of FBP1 in ovarian cancer cells, and the silencing FBP1 can enhance the sensitivity of ovarian cancer cells to carboplatin (5). Furthermore, a number of clinical trials have demonstrated that platinum-based drugs can significantly improve the pathological complete remission rate of neoadjuvant chemotherapy in patients with TNBC (6-8), particularly for patients with the BRCA1/2 mutation (9). Cisplatin is a commonly used chemotherapeutic drug in patients with TNBC. Studies have reported that cisplatin interacts with DNA to form intra-chain cross-linking and inter-strand cross-linking, and exerts antitumor effects by activating multiple DNA repair pathways and enhancing the DNA damage repair processes $(10,11)$. However, the specific mechanisms underlying the effects of cisplatin on TNBC and FBP1 expression in TNBC remain unknown.

The human far upstream element (FUSE) binding protein 1 (FBP1) is a multifunctional DNA- and RNA-binding protein involved in diverse cellular processes, which regulates 
transcription, splicing and translation (12). FBP1 promotes cell proliferation, enhances cell migration and inhibits apoptosis by modulating complex networks (13). FBP1 is overexpressed in a variety of malignant tumors, such as hepatocellular carcinoma, ovarian cancer, nasopharyngeal carcinoma and breast cancer $(5,14-16)$. The overexpression of FBP1 has been shown to be associated with a lower overall survival rate in ovarian cancer and nasopharyngeal carcinoma $(5,16)$. Therefore, FBP1 is considered a proto-oncogene. FBP1 was originally identified as a factor that binds the FUSE motif in the promoter of the oncogene c-Myc (13). Moreover, c-Myc, the deubiquitinating enzyme ubiquitin specific peptidase 29 and the cell cycle inhibitor p21, are regulated by FBP1 (17).

The present study hypothesized that FBP1 plays an important role in promoting breast cancer development, and therefore a lack of FBP1 may interfere with TNBC cells exiting the cell cycle and migration. It was identified that the silencing of FBP1 enhanced the sensitivity of TNBC cells to cisplatin. Additionally, cisplatin treatment inhibited TNBC cell viability and promoted cell apoptosis by inhibiting the expression of FBP1. Therefore, FBP1 may be a potential novel biological target for the treatment of TNBC.

\section{Materials and methods}

Clinical sample collection. Informed consents for the use of their samples in scientific research were obtained from all patients. The present study was conducted after the protocol was approved by the Medical Ethics Committee of Guangzhou Red Cross Hospital of Jinan University (approval no. 2015-045-01). For immunohistochemical analysis, a total of 54 breast tissue samples, including 27 breast cancer tissues and the corresponding 27 para-carcinoma normal breast tissues, were collected from the Department of Breast, Guangzhou Red Cross Hospital from January, 2015 to December, 2018 with a median age of 60 (from 47 to 85 years). None of the patients had received any pre-operative therapies, such as chemotherapy, radiotherapy, endocrine therapy, targeted therapy or immunotherapy prior to the study.

Antibodies and reagents. GAPDH (\#5174), c-Myc (\#13987), cleaved caspase-3 (\#9661), cyclin A2 (\#91500), cyclin B1(\#12231), cdc2 (\#77055), p-cdc2 (\#4539) and matrix metalloproteinase (MMP)2 (\#13132) antibodies were purchased from Cell Signaling Technology, Inc. FBP1 (\#ab213525) antibody was obtained from Abcam. All antibodies were used at the concentrations recommended by the supplier. Fetal bovine serum (FBS) and Dulbecco's modified Eagle's medium (DMEM) were purchased from Gibco; Thermo Fisher Scientific, Inc. Penicillin and streptomycin sulfate were obtained from Hyclone (Logan, UT, USA). Cisplatin was purchased from Sigma-Aldrich; Merck KGaA. The CellTiter $96{ }^{\circledR}$ AQueous One Solution proliferation assay kit (3-(4,5-dimethylthiazol-2-yl)-5-(3-carboxymethoxyphenyl)2-(4-sulfophenyl)-2H-tetrazolium, inner salt; MTS) was provided by Promega Corporation.

Immunohistochemical staining. Paraffin tissue sections (4- $\mu \mathrm{m}$-thick) were dewaxed by xylene, hydrated in a gradient alcohol and an aqueous solution, and then subjected to antigen retrieval using a citric acid buffer $(\mathrm{pH}$ 6.0). The peroxidase was blocked with $3 \% \mathrm{H}_{2} \mathrm{O}_{2}$ for 10 min and $10 \%$ BSA (Boster Biological Technology Co. Ltd.) for $30 \mathrm{~min}$ at room temperature. Rabbit anti-FBP1 antibody (diluted 1:500) was then incubated with the sections overnight at $4^{\circ} \mathrm{C}$. After washing with phosphate-buffered saline (PBS: $\mathrm{KH}_{2} \mathrm{PO}_{4}$, $2 \mathrm{mM} ; \mathrm{Na}_{2} \mathrm{HPO}_{4}, 8 \mathrm{mM}$; $\mathrm{NaCl}, 136 \mathrm{mM}$ and $\mathrm{KCl}, 2.6 \mathrm{mM}$, $\mathrm{pH}$ 7.2-7.4), the appropriate amount of secondary antibody (1:2,000; IHC Detection Reagent (HRP, rabbit) \#8114, Cell Signaling Technology, Inc.) was incubated with the sections for $1 \mathrm{~h}$ at room temperature. DAB (\#ZLI-9018, Beijing Zhongshan Jinqiao Biotechnology Co., Ltd.) was used to display color reaction at room temperature for $5 \mathrm{~min}$, and hematoxylin (\#ZLI-9620, Beijing Zhongshan Jinqiao Biotechnology Co., Ltd.) was used for counterstaining at room temperature for 10 min, and the slices were then dehydrated by immersing them in $75,80,90,95 \%$ and absolute alcohol for 3 min each and sealed. Image processing and analysis were performed using ImagePro Plus 6.0 software (Media Cybernetics, Inc.). The intensity of the immunohistochemistry was expressed as the integrated optical density (IOD) of the DAB brown reaction product. Each sample was measured 5 times separately and the results are expressed as the means \pm standard deviation (SD).

Cell culture and generation of stable cells in which FBPI was knocked down. The TNBC cells, MDA-MB-231 and normal breast cells, MCF-10A were purchased from the Chinese Academy of Sciences Cell Bank. The cells were cultured in DMEM containing $10 \% \mathrm{FBS}, 100 \mathrm{U} / \mathrm{ml}$ penicillin, $100 \mu \mathrm{g} / \mathrm{ml}$ streptomycin in $37^{\circ} \mathrm{C}$ and $5 \% \mathrm{CO}_{2}$ incubator. The lentivirus containing the FBP1 silenced sequence (sc 43760) and the control lentivirus (sc 108080) were purchased from the Santa Cruz Biotechnology, Inc., and $10 \mu \mathrm{g}$ each of these were transfected into the MDA-MB-231 cells according to the protocol provided by the manufacturer. After screening with $10.0 \mu \mathrm{g} / \mathrm{ml}$ of puromycin for approximately 2 weeks, the cells were collected and the silencing of FBP1 was determined by western blot analysis; these cells were then termed as 'FBP1 knockdown' (FBP1-KD) and FBP1 normal control (FBP1-C) MDA-MB-231 cells, respectively.

Western blot analysis. After the TNBC MDA-MB-231 cells were treated without or with cisplatin $(20,40$ and $80 \mu \mathrm{M})$ for $48 \mathrm{~h}$, they were collected and lysed in a modified RIPA buffer [150 mM NaCl, 1\% NP-40, $50 \mathrm{mM}$ Tris-Cl (pH 8.0) and $0.1 \% \mathrm{SDS}$ ] supplemented with PMSF $(1 \mathrm{mM})$ protease and phosphatase inhibitor. The homogenate was incubated in ice for $30 \mathrm{~min}$ and centrifuged at $12,000 \mathrm{x}$ g for $15 \mathrm{~min}$ at $4^{\circ} \mathrm{C}$. The protein concentrations were determined by double-acetyl acid protein analysis (Pierce; Thermo Fisher Scientific, Inc.), and the protein samples were then dissolved by a $12 \%$ SDS-PAGE gel and transferred to a polyvinylidene difluoride filter membranes (PVDF) (Merck KGaA). Following transfer, the membranes were blocked with $5 \%$ skim milk in TBS-Tween (0.05 M Tris, 0.15 M NaCl, pH 7.5, 0.2\% Tween-20) for $1 \mathrm{~h}$ and then incubated at $4{ }^{\circ} \mathrm{C}$ overnight with the primary antibodies (FBP1, 1:1,000; c-MYC, 1:500; Cyclin A2, 1:1,000; Cyclin B1, 1:1,000; p-cdc2, 1:1,000; cdc2, 1:1,000; MMP-2, 1:1,000; C-Caspase-3, 1:1,000; and GAPDH, 1:1,000). The membranes were then washed 3 times with TBST and then incubated 
with anti-rabbit/mouse HRP-labeled secondary antibodies (goat anti-rabbit IgG antibody, 1:5,000, \#ARG65351; goat anti-mouse IgG antibody, 1:5,000, \#ARG65350; Taiwan Arigo Biolaboratories Corp.) for $1 \mathrm{~h}$ at room temperature, and detected using the ECL-Plus detection system (Pierce; Thermo Fisher Scientific, Inc.). Relative abundance was quantified by densitometry using Quantity One 4.6.7 software (Bio-Rad Laboratories, Inc.).

Reverse transcription-quantitative polymerase chain reaction $(R T-q P C R)$. Total RNA was extracted from the FBP1-KD and FBP1-C MDA-MB-231 cells using TRIzol reagent (Takara Biotechnology Co., Ltd.) and cDNA synthesis was carried out by reverse transcription using PrimeScriptTM RT Master Mix (Takara Biotechnology Co., Ltd.) according to the manufacturer's protocol. PCR amplification of FBP1, c-Myc and GAPDH was carried out using TB GreenTM Premix Ex TaqTM (Takara Biotechnology Co., Ltd.). The primers used were as follows: FBP1 forward, 5'-GGAACTCCAATGGA CCAATACAAC-3' and reverse, 5'-AGTGAGGTAATAAG CAGCCAAG-3'; c-Myc forward, 5'-CGGTGCAGCCGTAT TTCTACT-3' and reverse, 5'-TTCCAGATATCCTCGCT GGG-3'; and GAPDH forward, 5'-GAGGTGAAGGTCGGA GTC-3' and reverse, 5'-GAGAGAGAGATGATGGGATTC-3'. The amplification conditions were as follows: initial denaturation at $95^{\circ} \mathrm{C}$ for $5 \mathrm{~min}$, followed by 40 cycles of denaturation $95^{\circ} \mathrm{C}$ for $5 \mathrm{sec}$, annealing at $60^{\circ} \mathrm{C}$ for $20 \mathrm{sec}$. All reactions were performed on an Applied Biosystems 7300 PCR system (Applied Biosystems; Thermo Fisher Scientific, Inc.). Relative quantification was performed using the $2^{-\Delta \Delta \mathrm{Cq}}$ method (18). Each PCR amplification was performed in triplicate to verify the results.

Cell viability assay. For the cell viability assay, approximately $1 \times 10^{3}$ FBP1-C and FBP1-KD cells were added to a 96-well plate and were incubated without or with cisplatin (20,40 and $80 \mu \mathrm{M}$ ) for 24,48 and $72 \mathrm{~h}$. Cell viability was determined by MTS assay in accordance with the CellTiter 96 Aqueous One Solution Viability assay manual. The absorbance was read at $490 \mathrm{~nm}$ with an automated plate reader (ELX800, BioTek Instruments Inc.). The experiment was repeated at least 3 times.

Colony formation assay. The FBP1-C and FBP1-KD MDA-MB-231 cells $\left(5 \times 10^{3}\right.$ cells/plate) were plated in $60 \mathrm{~mm}$ plates and cultured for 14 days without or with 20, 40 and $80 \mu \mathrm{M}$ of cisplatin. Colonies were washed with PBS, fixed with $10 \%$ formalin for $10 \mathrm{~min}$ at room temperature and stained with $1 \%$ (w/v) crystal violet (\#C8470, Beijing Solarbio Science \& Technology Co., Ltd.) for $10 \mathrm{~min}$ at room temperature. The colony formation images were captured using a scanner (x1 magnification, UMAX).

Cell cycle and cell apoptosis analysis. Flow cytometry was used to analyze cell cycle distribution and apoptosis. FBP1-C and FBP1-KD cells were treated without or with cisplatin (20, 40 and $80 \mu \mathrm{M}$ ) for $48 \mathrm{~h}$. The cells were collected and washed twice with cold PBS, and the cells were then resuspended into a single cell suspension with PBS, supplemented with $200 \mu \mathrm{l}$ binding buffer. This was followed by the addition of $10 \mu \mathrm{l}$ of
Annexin V-FITC and $10 \mu \mathrm{l}$ of $50 \mu \mathrm{g} / \mathrm{ml}$ propidium iodide (PI; BD Biosciences) in PBS containing 1\% Triton X-100 at room temperature for $15 \mathrm{~min}$. The data were acquired using a BD FACSCAN flow cytometer (FACSAria II, BD Biosciences) and analyzed using BD ModFit LT version 3.3 (BD Biosciences).

Wound healing and Transwell invasion assays. The FBP1-C and FBP1-KD cells were treated with mitomycin for $4 \mathrm{~h}$, then cross-sectioned with $100 \mu \mathrm{l}$ tips in a 6-well plate, and cultured for $48 \mathrm{~h}$. After fixing with $4 \%$ paraformaldehyde solution at room temperature for $15 \mathrm{~min}$, microscopic examination was performed and the cell migration distance was determined. Matrigel was preliminarily spread in a 12-well Transwell, and the cultured FBP1-C and FBP1-KD cells were prepared in a $1 \times 10^{5}$ cell $/ \mathrm{ml}$ suspension with $1 \%$ FBS culture solution. A total of $200 \mu \mathrm{l}$ cell suspension was added to the upper chamber, and $600 \mu \mathrm{l}$ of $10 \%$ FBS cell culture medium was added to the lower chamber. After the cells in the Transwell were cultured at $37^{\circ} \mathrm{C}$ for $48 \mathrm{~h}$, they were stained with $0.1 \%$ crystal violet, and the number of invaded cells was then counted using a microscope (BX63, Olympus Corporation). Images were acquired using an Olympus inverted microscope (Olympus Corporation) at a magnification of $\mathrm{x} 200$.

Statistical analysis. Values are presented as the means \pm SD. Data were analyzed using the Student's t-test and two-way ANOVA (followed by Tukey's post hoc test) using SPSS 18.0 software (SPSS, Inc., Chicago, IL, USA). The correlation between FBP1 and c-Myc expression was checked by Spearman's rank correlation analysis. $\mathrm{P}<0.05$ was considered to indicate a statistically significant difference.

\section{Results}

Overexpression of FBPI and c-Myc in breast cancer tissues. To identify the association between FBP1 expression and breast cancer development, the expression levels of FBP1 and c-Myc, a target of FBP1, were measured in 4 pairs of breast cancer tissues and their corresponding para-carcinoma normal tissues by western blot analysis. The protein expression of FBP1 in breast cancer tissues and normal breast tissues is shown in Fig. 1A. The relative protein expression of FBP1 in cancer tissues was significantly higher compared with that in normal tissues (Fig. 1B). Since FBP1 binds to the FUSE DNA sequence upstream of the c-Myc promoter and regulates its expression (19), the expression of c-Myc in these breast cancer tissues was also examined. As was expected, the protein expression of c-Myc was positively associated with FBP1 expression, and the expression of c-Myc in cancer tissues was significantly higher compared with that in normal tissues (Fig. 1A-C).

It is critical to understand the underlying molecular mechanisms of TNBC in order to be able to identify novel therapeutic targets for its treatment. The present study compared the expression of FBP1 and c-Myc in the normal breast cell line, MCF-10A, and in the TNBC cancer cell line, MDA-MB-231. The protein expression levels of FBP1 and c-Myc are illustrated in Fig. 1D. The protein expression of FBP1 in the MDA-MB-231 cells was 1.66-fold higher than that in the MCF-10A cells (Fig. 1D and E). The protein expression 
A

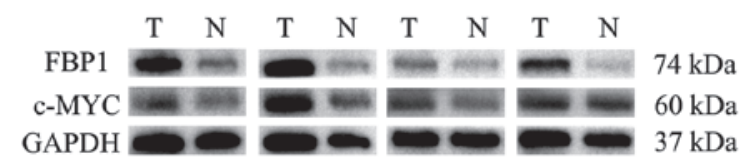

$\mathrm{C}$

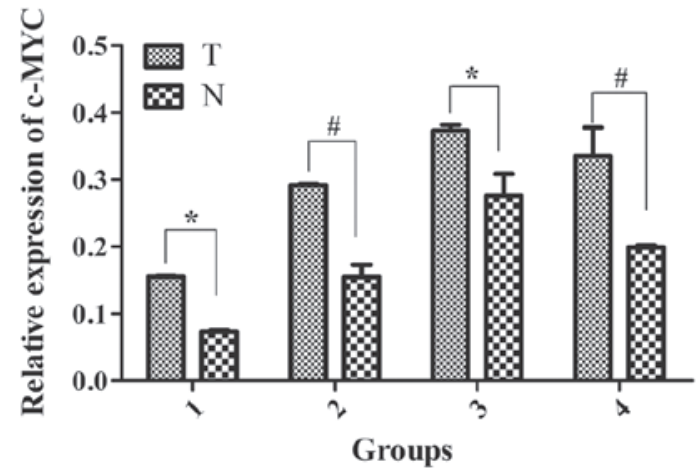

E

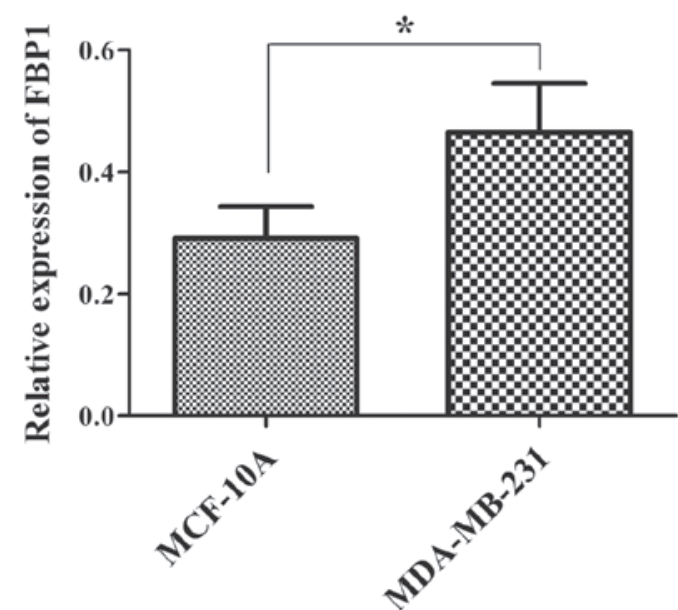

$\mathrm{B}$

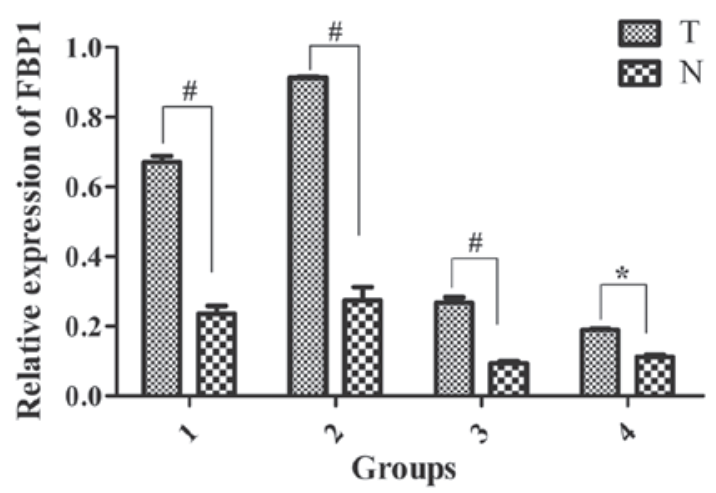

$\mathrm{D}$

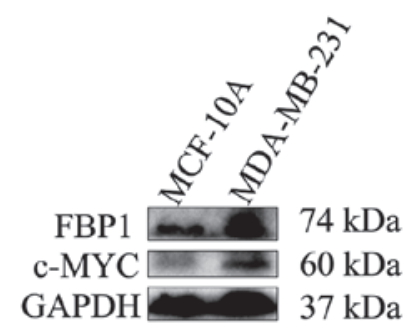

$\mathrm{F}$

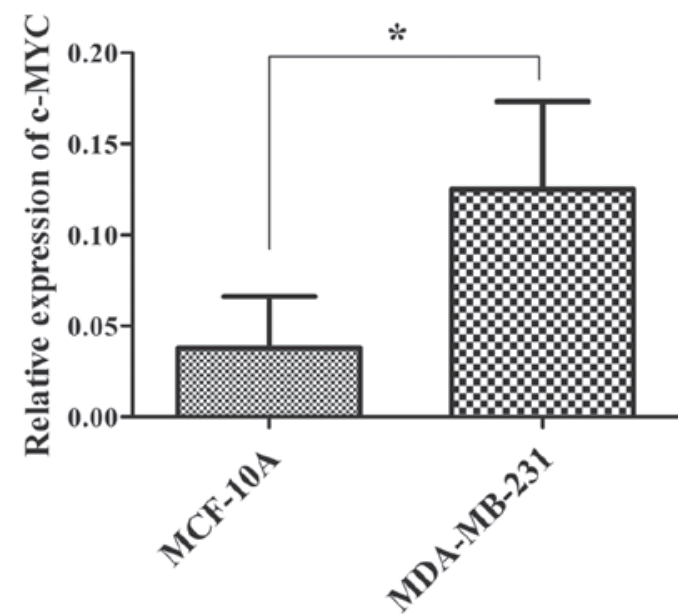

Figure 1. Overexpression of FBP1 and c-Myc in breast cancer tissues and cells. (A) FBP1 and c-Myc expression levels in 4 pairs of breast tumor (T) and para-carcinoma normal $(\mathrm{N})$ tissues detected by western blot analysis. (B and C) Relative protein expression levels of FBP1 and c-Myc against GAPDH. The data are the means $\pm \mathrm{SD}$ of 3 independent experiments. ${ }^{*} \mathrm{P}<0.05,{ }^{\sharp} \mathrm{P}<0.01$. (D) FBP1 and c-Myc expression levels in the normal breast cell line, MCF-10A, and the TNBC cancer cell line, MDA-MB-231, detected by western blot analysis. (E and F) Relative protein expression levels of FBP1 and c-Myc against GAPDH. The data are the means $\pm \mathrm{SD}$ of 3 independent experiments. "P<0.05.

of c-Myc in the MDA-MB-231 cells was 2.30-fold higher than that of the MCF-10A cells (Fig. 1D and F).

To further investigate the expression of FBP1 and c-Myc in a larger number of tissues, 54 samples from patients with breast cancer were examined by immunohistochemical staining. As shown in Fig. 1G, FBP1 was predominantly localized in the nuclei of the breast cancer cells (Fig. 1G). The IOD of FBP1 was higher in breast cancer tissues compared with that in para-carcinoma normal tissues (Fig. 1H). The results also demonstrated that c-Myc expression was increased in accordance with the increased expression of FBP1. In addition, the IOD of c-Myc was higher in breast cancer tissues compared with breast para-carcinoma normal tissues (Fig. 1G and I). The correlation between FBP1 and c-Myc expression was also investigated using Spearman's rank correlation analysis, and
c-Myc expression positively correlated with FBP1 expression (Fig. 1J, r=0.6726, $\mathrm{P}=0.0001$ ).

Cisplatin treatment decreases FBP1 expression in advanced TNBC cells. Cisplatin is frequently used in the treatment of breast cancer, including TNBC. In the present study, to determine the effects of cisplatin on FBP1 expression, western blot analysis was performed to examine the expression of FBP1 in the MDA-MB-231 TNBC cells with or without cisplatin treatment. FBP1 expression was downregulated by cisplatin in advanced TNBC cells (Fig. 2A). Cisplatin (40 and $80 \mu \mathrm{M}$ ) significantly inhibited FBP1 expression (Fig. 2B). c-Myc expression was also downregulated by cisplatin, and treatment with 40 and $80 \mu \mathrm{M}$ of cisplatin significantly inhibited c-Myc expression. Both the expression levels of FBP1 and c-Myc 
G
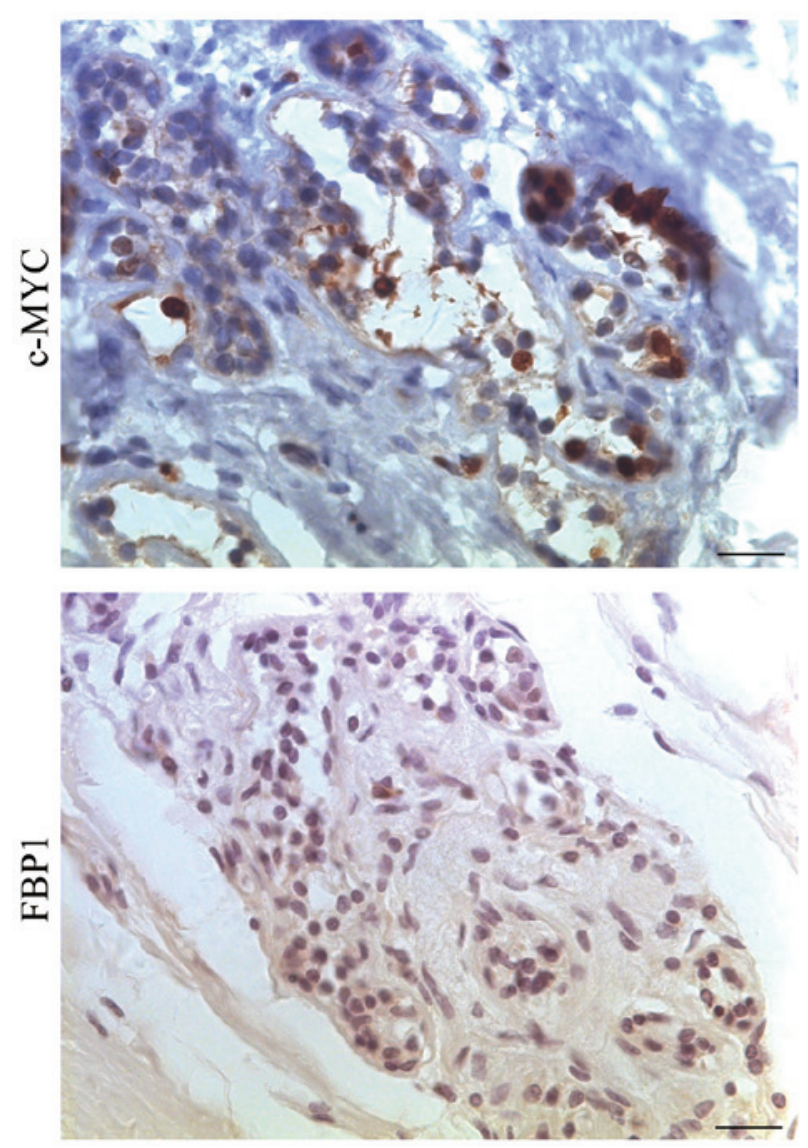

$\mathrm{N}$

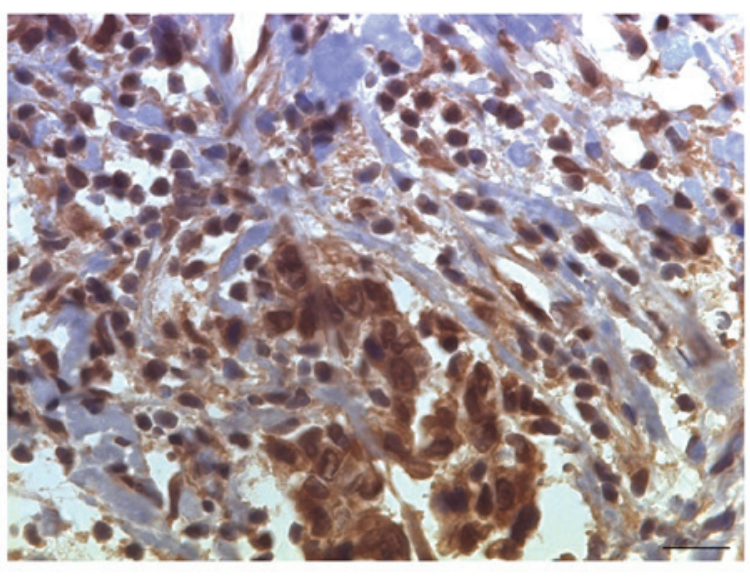

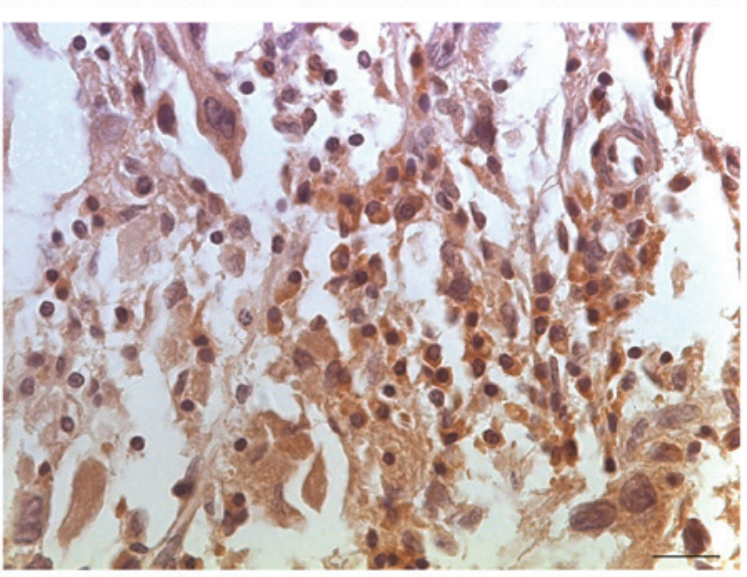
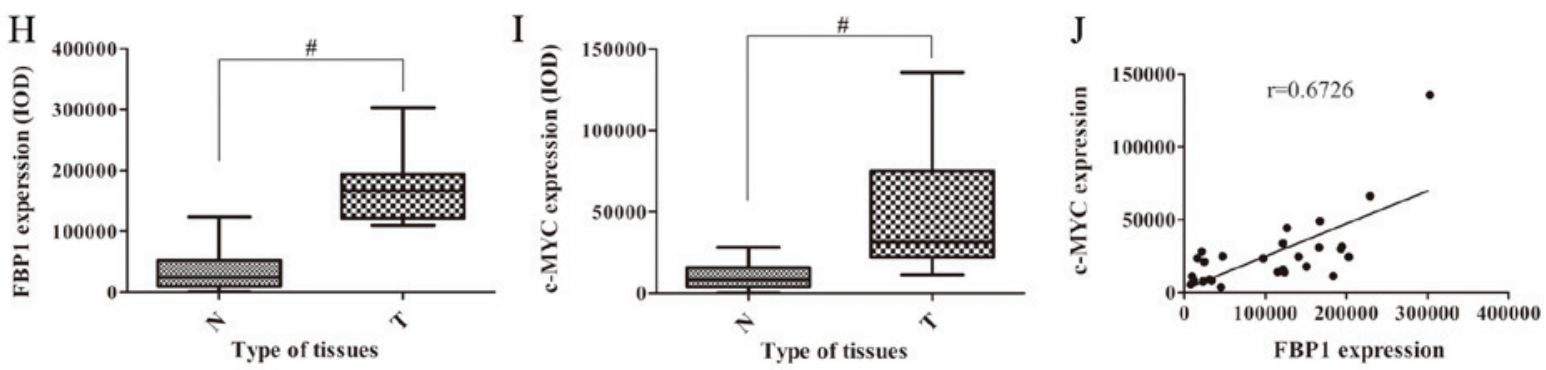

Figure 1. Continued. Overexpression of FBP1 and c-Myc in breast cancer tissues and cells. (G) FBP1 and c-Myc expression in breast tumor (T) and para-carcinoma normal $(\mathrm{N})$ tissues detected by immunohistochemical staining (magnification, x630; scale bar, $20 \mu \mathrm{m}$ ). (H and I) Quantitative analysis of (E) FBP1 and (F) c-Myc expression in breast tumor and para-carcinoma normal tissues by Image Pro Plus 6 software. (J) Correlation between FBP1 and c-Myc expression in breast tissues analyzed by Spearman's rank correlation analysis. The intensity of DAB brown reactions was expressed as integral optical density (IOD). ${ }^{\text {"}} \mathrm{P}<0.01$. FBP1, far upstream element binding protein 1.

were decreased by cisplatin in a dose-dependent manner (Fig. 2A and B).

FBP1 promotes cell proliferation and G2/M phase transition in TNBC cells. Since FBP1 was positively associated with breast cancer development, it was hypothesized that FBP1 may play a role in cell proliferation, cell cycle progression and the apoptosis of breast cancer cells. To investigate the possible roles of FBP1 in cell proliferation, the MDA-MB-231 cells were transfected with shRNA to create a cell line in which FBP1 was knockdown, which was termed FBP1-KD cells. FBP1 normal cells served as the control group and were termed FBP1-C cells. The expression of FBP1 and c-Myc in the FBP1-KD MDA-MB-231 cells was significantly decreased compared with its expression in the FBP1-C MDA-MB-231 cells, as determined by RT-qPCR and western blot analysis (Fig. 2C-E). These results demonstrated that a stable FBP1-KD cell line was constructed.

As illustrated in Fig. 3A and B, the proliferation of the FBP1-KD cells was significantly decreased compared with that of the FBP1-C cells, according to MTS assay and colony formation assay. The colonies of FBP1-KD cells were significantly smaller and fewer than those of the FBP1-C cells (Fig. 3B). However, Annexin-V450/7-ADD flow cytometry revealed that the percentage of apoptotic cells was $\sim 5.0 \%$ in both the FBP1-C and FBP1-KD cells (Fig. 3C). These data indicated that FBP1 knockdown affected the proliferation of the TNBC MDA-MB-231 cells, but did not affect cell apoptosis. 
A

Cisplatin

$(\mu \mathrm{M}) \quad 0 \quad 20 \quad 40 \quad 80$

FBP1 $-2-74 \mathrm{kDa}$

c-MYC $=60 \mathrm{kDa}$

GAPDH $20-37 \mathrm{kDa}$

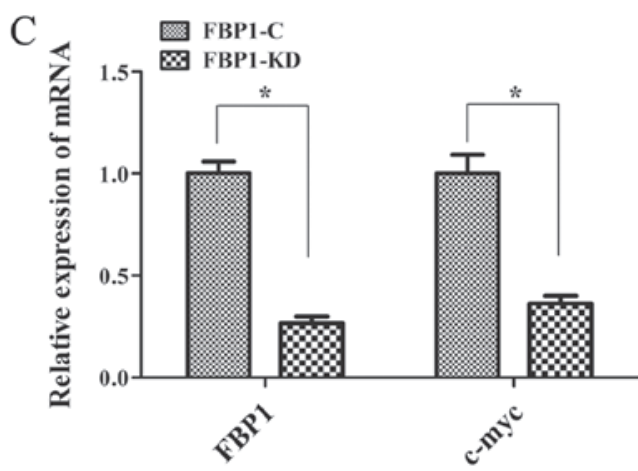

$\mathrm{D}$

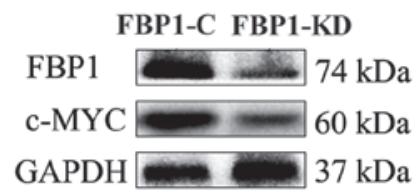

B

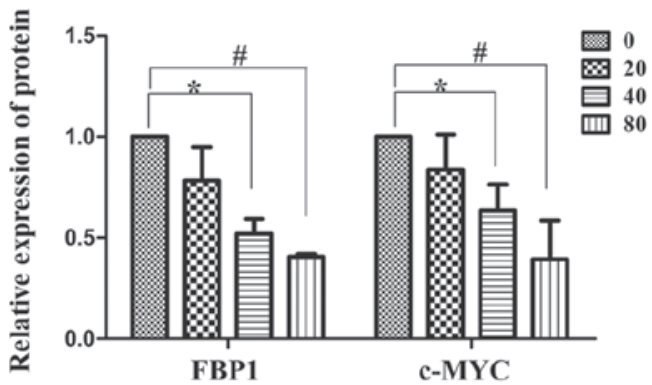

$\mathrm{E}$

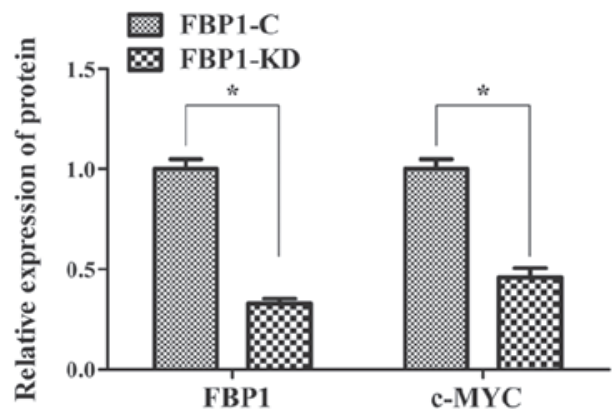

Figure 2. Cisplatin treatment reduces the expression of FBP1 and c-Myc in tje TNBC MDA-MB-231 cells and the generation of MDA-MB-231 cells in which FBP1 was knocked down. (A) Cisplatin treatment reduced the expression of FBP1 and c-Myc in TNBC MDA-MB-231 cells, as shown by western blot analysis. (B) Relative expression levels of FBP1 and c-Myc against GAPDH determined by western blot analysis. (C) Expression of FBP1 and c-Myc in FBP1-C and FBP1-KD MDA-MB-231 cells determined by RT-qPCR. (D) Expression of FBP1 and c-Myc in FBP1-C and FBP1-KD MDA-MB-231 cells determined by western blot analysis. (E) Relative expression levels of FBP1 and c-Myc against GAPDH determined by western blot analysis. The data are the means \pm SD of 3 independent experiments. ${ }^{*} \mathrm{P}<0.05,{ }^{\#} \mathrm{P}<0.01$. FBP1-C, FBP1 control; FBP1-KD, FBP1 knockdown; FBP1, far upstream element binding protein 1.

To certify the function of FBP1 in cell cycle transition, the cell cycle phase distribution of FBP1-C and FBP1-KD MDA-MB-231 cells was analyzed by flow cytometry. As shown in Fig. 3D and E, the percentage of cells in the G2 phase was 11.05 and $34.06 \%$ in the FBP1-C and FBP1-KD cells, respectively. By contrast, the percentages of cells in the $\mathrm{S}$ and $\mathrm{G} 1$ phases were 34.91 and $54.03 \%$ in the FBP1-C cells, and 8.74 and $57.19 \%$ in the FBP1-KD cells, respectively. These data indicated that the transition from the G2/M/G1 to the $\mathrm{S}$ phase was significantly inhibited by FBP1 knockdown. Additionally, the expression levels of G2 phase markers, such as cyclin A2, cyclin B1, p-cdc2 and cdc2 were measured. The protein expression of cyclin A2 was lower in the FBP1-KD cells compared with the FBP1-C cells. However, the expression levels of cyclin B1, p-cdc2 and cdc2 were higher in the FBP1-KD cells compared with the FBP1-C cells (Fig. 3F and G). The relative ratio of p-cdc2 (p-cdc2/GAPDH) against cdc2 (cdc2/GAPDH) in the FBP1-KD cells was higher than that in the FBP1-C cells (Fig. 3F and G). These data suggested that FBP1 knockdown affected the cell cycle transition by arresting cells in the G2/G1 phase.

FBP1 knockdown inhibits cell migration and invasion. Cell migration and invasion are critical for cancer progression. A previous study by the authors demonstrated that FBP1 contributed to tumor cell migration and invasion in endothelial cancer (24). A wound healing assay in the present study revealed that FBP1 knockdown decreased the migration of
MDA-MB-231 cells. As shown in Fig. 4A, the migration rate of the FBP1-KD MDA-MB-231 cells was slower compared with that of the FBP1-C cells at 24 and $48 \mathrm{~h}$. Additionally, the results from Transwell assay revealed that FBP1 knockdown significantly inhibited cell invasion to the bottom chambers (Fig. 4B and C).

A previous study demonstrated that MMPs are key regulators of cell migration (20). The present study thus investigated the expression of MMP-2 in the FBP1 C and FBP1-KD MDA-MB-231 cells. FBP1 knockdown inhibited the expression of MMP-2 (Fig. 4D and E). These data suggest that FBP1 promotes cancer cell migration and facilitates cell metastasis.

FBPI knockdown enhances the sensitivity of TNBC cells to cisplatin. The sensitivity of TNBC cells to drugs is low and this is postulated as one of the reasons for the poor prognosis of patients with TNBC. In the present study, to investigate the role of FBP1 in the drug sensitivity of TNBC cells, the effects of FBP1 on the cisplatin-induced toxicity of MDA-MB-231 cells were examined. The FBP1-C and FBP1-KD MDA-MB-231 cells were incubated with gradient concentrations $(20,40$ and $80 \mu \mathrm{M})$ of cisplatin for 24 to $72 \mathrm{~h}$. Cell viability, which is used to assess drug sensitivity, was evaluated by MTS assay. The viability of the FBP1-C and FBP1-KD cells decreased following cisplatin treatment and the decrease was dose-dependent (Fig. 5A-C). The viability of the FBP1-KD cells decreased more prominently that that of the FBP1-C cells following treatment with 20,40 and $80 \mu \mathrm{M}$ 
A

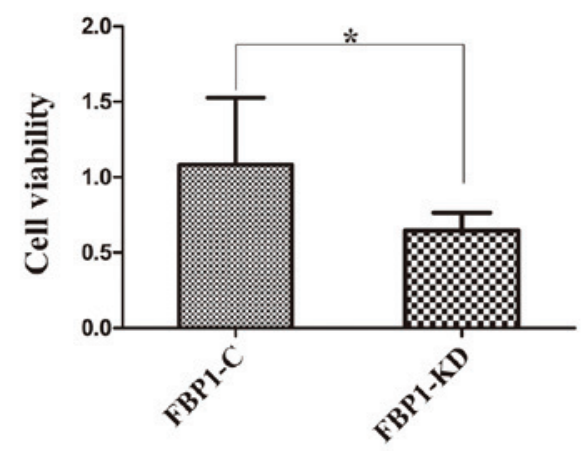

$\mathrm{C}$

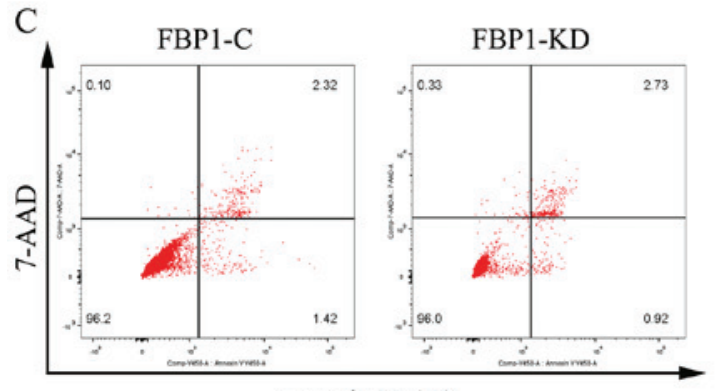

Annexin V-450

$\mathrm{E}$

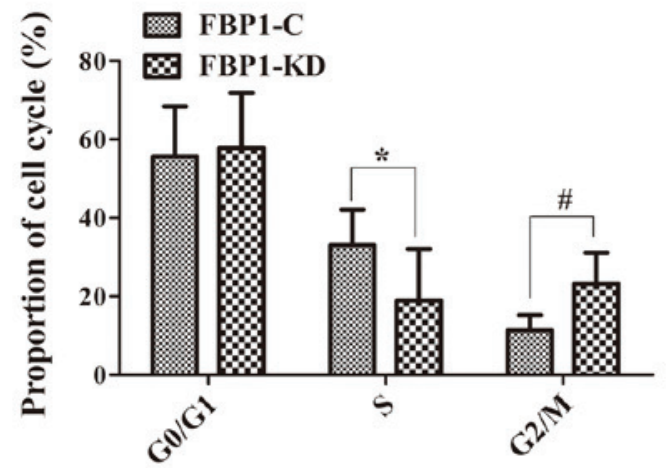

$\mathrm{G}$

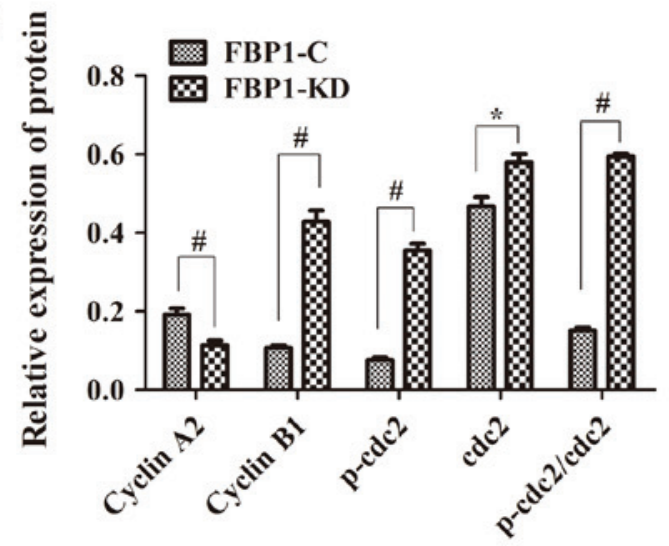

B

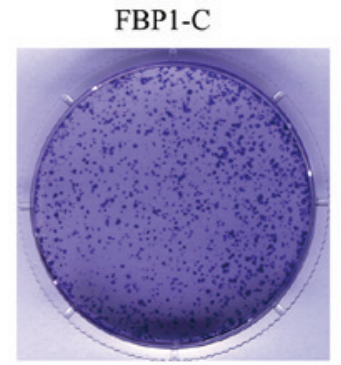

FBP1-KD

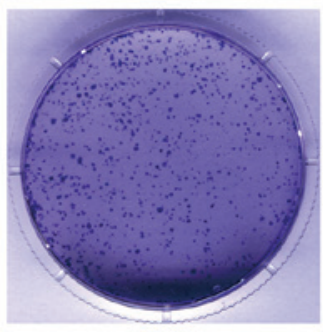

$\mathrm{D}$

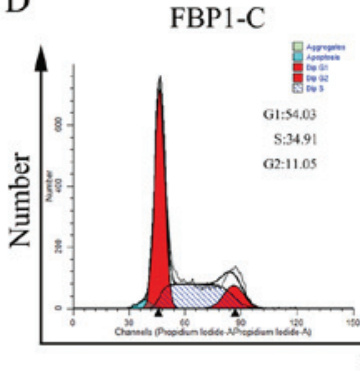

FBP1-KD

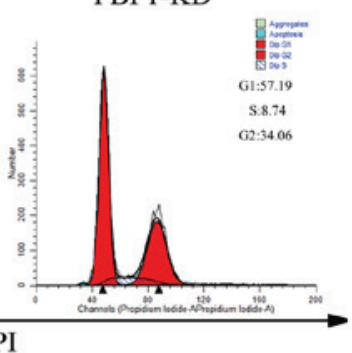

F

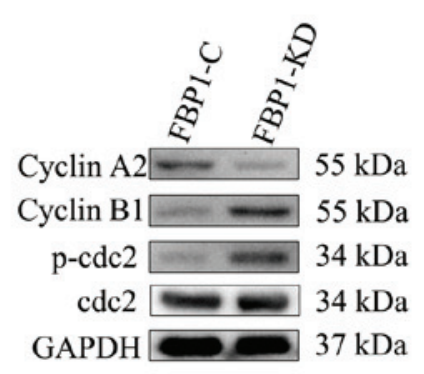

Figure 3. Knockdown of FBP1 inhibits cell proliferation and G2/M phase transition in TNBC MDA-MB-231 cells. (A) FBP1 knockdown decreased cell proliferation as shown by MTS assay. (B) FBP1 knockdown suppressed cell colony formation. Equal numbers of FBP1-C and FBP1-KD MDA-MB-231 cells were seeded onto $60-\mathrm{mm}$ plates and incubated for 14 days (x1 magnification; diameter of the dish was $60 \mathrm{~mm}$ ). (C) FBP1 knockdown did not affect the apoptosis of FBP1-C and FBP1-KD MDA-MB-231cells as analyzed by flow cytometry. (D) Cell cycle distribution of FBP1-C and FBP1-KD MDA-MB-231 cells analyzed by flow cytometry. (E) Bar chart demonstrates the ratio of FBP1-C and FBP1-KD MDA-MB-231 cells in the G1, S and G2 phase. (F) Expression of $\mathrm{G} 2$ phase associated proteins (cyclin A2, cyclin B1 and p-cdc2) examined by western blot analysis. (G) Bar chart demonstrates the ratio of cyclin A2, cyclin B1, p-cdc2 and cdc2 proteins against GADPH and the relative ratio of p-cdc2 (p-cdc2/GAPDH) against cdc2 (cdc2/GAPDH) in FBP1-C and FBP1-KD MDA-MB-231cells. The data are the means \pm SD of 3 independent experiments. ${ }^{*} \mathrm{P}<0.05,{ }^{,} \mathrm{P}<0.01$. FBP1-C, FBP1 control; FBP1-KD, FBP1 knockdown; FBP1, far upstream element binding protein 1 .

cisplatin for $24 \mathrm{~h}(\mathrm{P}<0.05$ and $\mathrm{P}<0.01), 20$ and $40 \mu \mathrm{M}$ of cisplatin for $48 \mathrm{~h}(\mathrm{P}<0.01)$, and $20 \mu \mathrm{M}$ of cisplatin for $72 \mathrm{~h}$
$(\mathrm{P}<0.01)$. In addition, a colony formation assay was used to further confirm that FBP1 knockdown enhanced the sensitivity 
A $0 \mathrm{~h}$ $24 \mathrm{~h}$ $48 \mathrm{~h}$
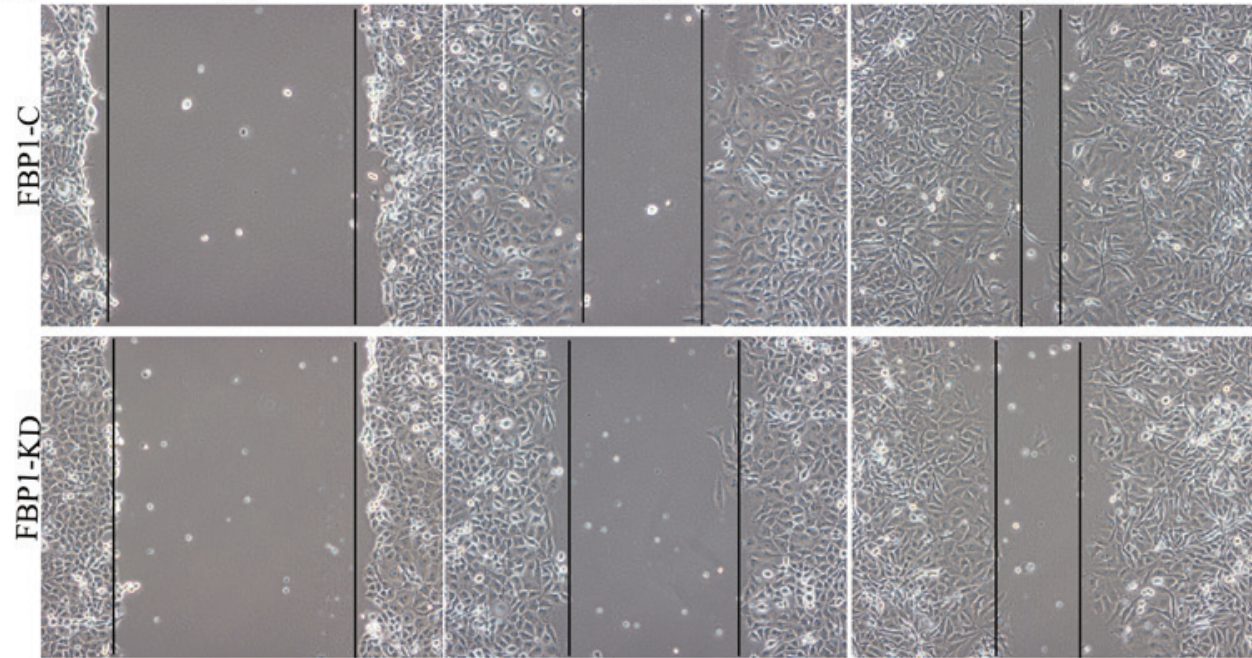

B

FBP1-C

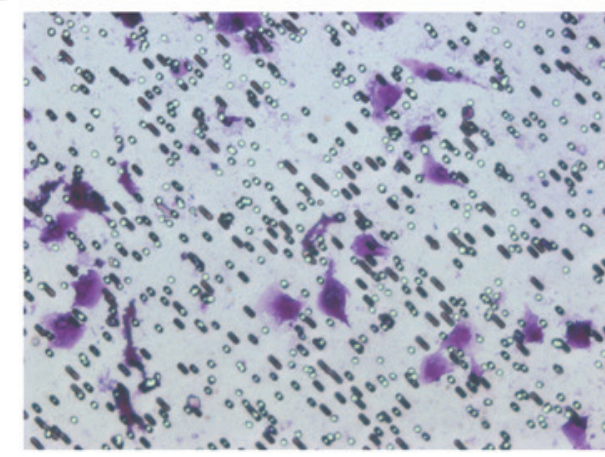

$\mathrm{C}$

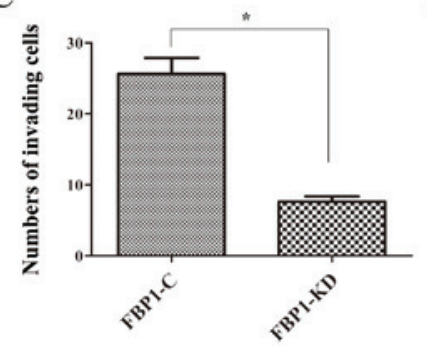

$\mathrm{D}$

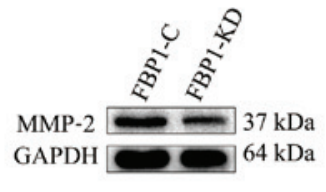

FBP1-KD

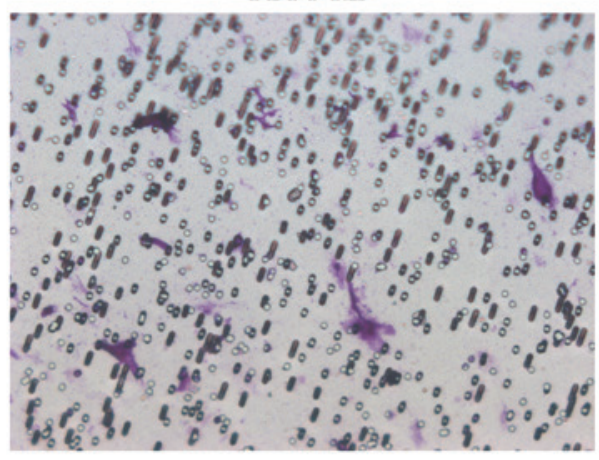

E

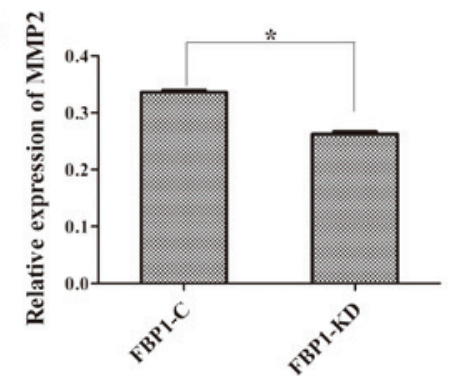

Figure 4. Knockdown of FBP1 inhibits cell migration and invasion. (A) Wound healing assay at 0, 24 and $48 \mathrm{~h}$, compared between the FBP1-C and FBP1-KD MDA-MB-231 cells. The migration of the cells was visualized with an inverted Nikon phase-contrast microscope (x100 magnification; scale bar, $100 \mu \mathrm{m}$ ). (B) Transwell invasion assay at $48 \mathrm{~h}$, compared between FBP1-C and FBP1-KD MDA-MB-231 cells. The crossed polycarbonate membrane cells were detected by crystal violet staining (x200 magnification; scale bar, $50 \mu \mathrm{m}$ ). (C) Bar chart demonstrates the numbers of cell invading cells. (D) expression of MMP-2 in FBP1-C and FBP1-KD MDA-MB-231 cells detected by western blot analysis. (E) Relative expression of MMP-2 against GADPH. Data are the means \pm SD of 3 independent experiments. "P<0.05. FBP1-C, FBP1 control; FBP1-KD, FBP1 knockdown; FBP1, far upstream element binding protein 1.

of TNBC cells to cisplatin. The FBP1-KD MDA-MB-231 cells formed fewer colonies than the FBP1-C MDA-MB-231 cells following treatment with $20 \mu \mathrm{M}$ cisplatin (Fig. 5D). These results demonstrated that FBP1 knockdown enhanced the sensitivity of TNBC cells to cisplatin.

FBP1 suppresses the cisplatin-induced apoptosis of TNBC cells. To verify the possible mechanisms underlying the high sensitivity of TNBC cells in which FBP1 was knocked down to cisplatin, the effects of cisplatin on the apoptosis of the FBP1-C and FBP1-KD MDA-MB-231 cells were examined by flow cytometry. As shown in Fig. 6A and B, the percentage of apoptotic cells was significantly higher in the FBP1-KD cells compared with that in the FBP1-C cells when the cells were treated with 40 and $80 \mu \mathrm{M}$ cisplatin for $48 \mathrm{~h}$. The expression of cleaved caspase-3 (C-Caspase-3), a typical characteristic of cell apoptosis, was examined by western blot analysis in the FBP1-C and FBP1-KD MDA-MB-231 cells. As shown in Fig. 6C and E, C-Caspase-3 expression was increased in both the FBP1-C and in FBP1-KD cells following treatment with 40 and $80 \mu \mathrm{M}$ cisplatin for $48 \mathrm{~h}$. Compared with the expression of C-Caspase-3 in the FBP1-C cells, the expression of C-Caspase-3 in the FBP1-KD cells was significantly higher. The expression of FBP1 in the FBP1-C and FBP1-KD cells decreased as the concentration of cisplatin increased 

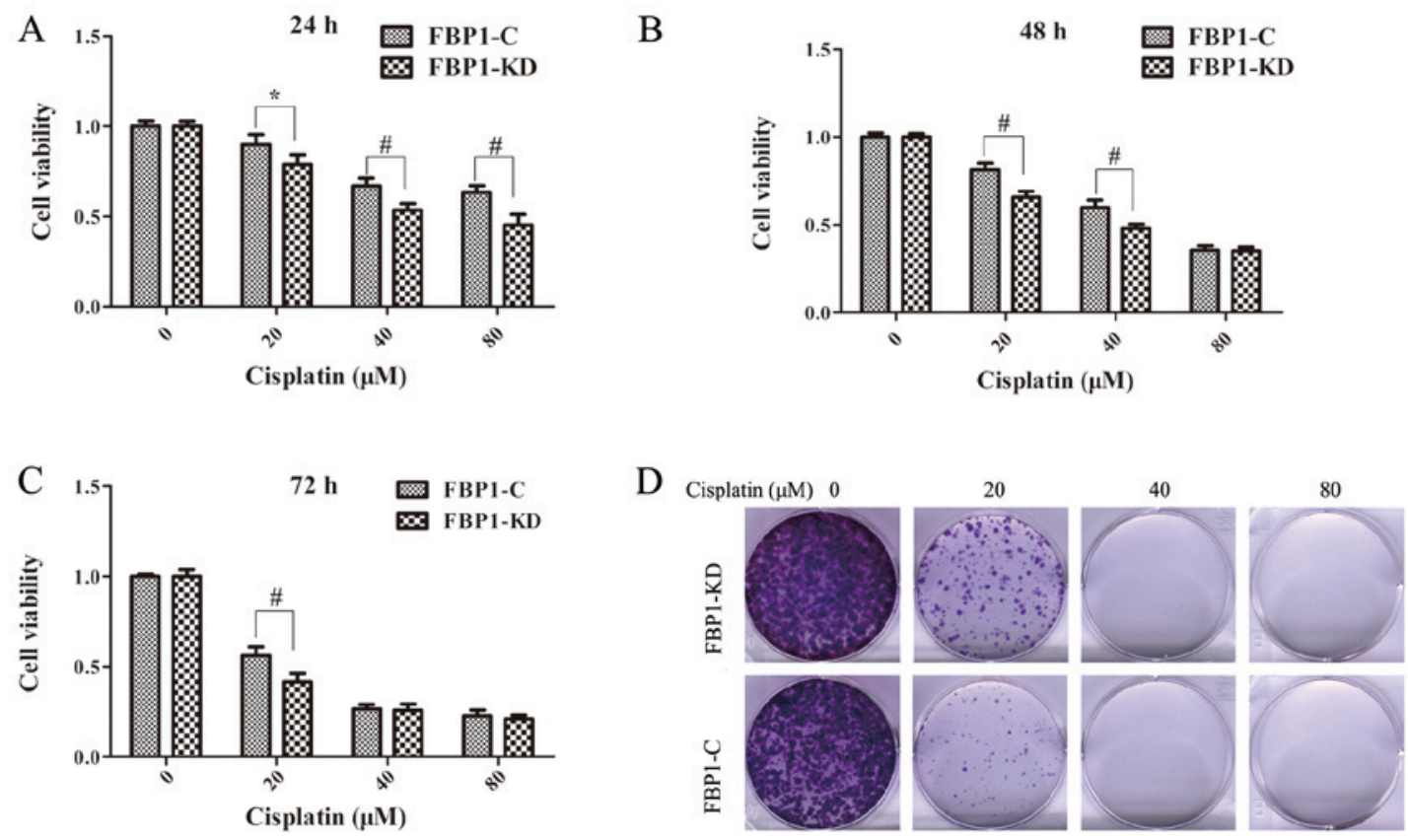

Figure 5. Knockdown of FBP1 enhances the sensitivity of TNBC MDA-MB-231 cells to cisplatin. (A-C) Viability of FBP1-C and FBP1-KD cells treated with the indicated concentrations of cisplatin for (A) 24, (B) 48 and (C) $72 \mathrm{~h}$ examined by MTS assay. (D) Colony formation of FBP1-C and FBP1-KD cells treated with the indicated concentrations of cisplatin for $48 \mathrm{~h}$. Equal numbers of FBP1-C and FBP1-KD MDA-MB-231 cells were seeded onto 60-mm plates and incubated for 14 days (x1 magnification; diameter of the dish was $60 \mathrm{~mm}$ ). ${ }^{\text {"P }}<0.05,{ }^{~} \mathrm{P}<0.01$. FBP1-C, FBP1 control; FBP1-KD, FBP1 knockdown; FBP1, far upstream element binding protein 1 .

(Fig. 6D). Based on these data, it was considered that FBP1 knockdown promoted cisplatin-induced apoptosis.

\section{Discussion}

According to the report of the American Cancer Society (21), breast cancer accounts for $29 \%$ of all new cancer diagnoses and was the leading cause of cancer-associated mortality in women aged 20-59 years in 2016. Although the treatments for breast cancer have improved over the past decades, the treatment efficacy is still limited due to drug toxicity and resistance, as well as the lack of dependable predictive and prognostic biomarkers (22). TNBC is a particular type of breast cancer that is ER-, PR- and HER-2-negative and cannot benefit from endocrine therapy. Thus, the investigation and identification of novel biomarkers and the relevant mechanisms of TNBC is of utmost importance.

FBP1 is an anti-apoptotic and anti-proliferative oncoprotein that acts by modulation of complex networks (12). Studies have indicated that FBP1 is overexpressed in a variety of malignant tumors, such as liver cancer, gastric cancer, esophageal squamous cell carcinoma, ovarian cancer and nasopharyngeal carcinoma, and FBP1 is associated with both a lower disease-free and overall survival in patients $(5,14-17,23,24)$. In a previous study by the authors, it was demonstrated that FBP1 expression was higher in epithelial ovarian cancer (EOC) tissues compared with in para-tissues, and that a higher expression of FBP1 was associated with EOC progression (25). The present study identified that the progression of breast cancer was positively associated with FBP1 expression, even though the exact numbers of clinical samples from Luminal A, Luminal B, HER-2 overexpression and TNBC patients were not know. In the future, the authors aim to collect more 4 types of clinical breast cancer samples, in order to analyze the effect of FBP1 on the development of breast cancer.

Cancer progression may be associated with cell viability, and a decreased cell viability may be induced by the suppression of cell cycle transition and the activation of cell death (25). The present study demonstrated that FBP1 knockdown significantly inhibited colony formation and increased the percentage of cells in the $\mathrm{G} 2$ phase. Cyclin B1 and p-CDC2, which are considered to be $\mathrm{G} 2 / \mathrm{M}$ phase transition inhibiting proteins, were induced by FBP1 knockdown. Conversely, cyclinA1, which is considered to be a $\mathrm{G} 2 / \mathrm{M}$ phase transition promoting protein, was suppressed by FBP1 knockdown. FBP1 knockdown did not affect cell apoptosis. These results suggest that FBP1 knockdown significantly suppresses the G2/M phase transition. However, FBP1 did not affect the death of TNBC cells.

Metastasis is a complex, multistep process that requires cancer cells to detach from the primary tumor, travel, survive and proliferate in distant organs $(26,27)$. MMPs have traditionally been considered to regulate a number of processes, including cell migration, angiogenesis, tumor expansion and metastasis $(28,29)$. In general, the expression of MMPs is low and can be upregulated during inflammation, tissue remodeling, wound healing and cancer progression (30). The present study demonstrated that FBP1 knockdown inhibited the migration and metastasis of TNBC cells, as well as the expression of MMP-2, which is an important member of the MMP family. These results suggested that FBP1 knockdown decreased the migration and metastasis via the inhibition of MMP-2 expression. It has been reported that the major mechanism regulating MMP expression is transcription. The majority of members of the MMP family share common cis-acting elements in their promoters and the promoters contain multiple elements that 
A Cisplatin $(\mu \mathrm{M}) 0$

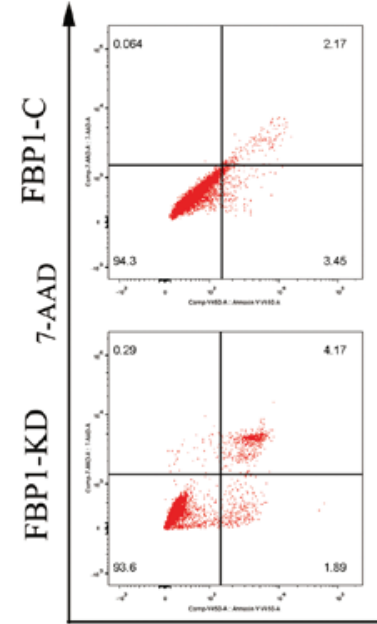

20

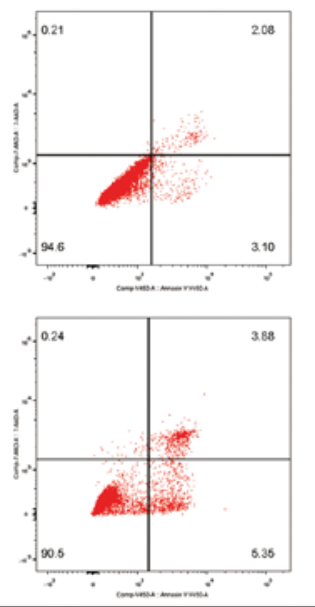

40

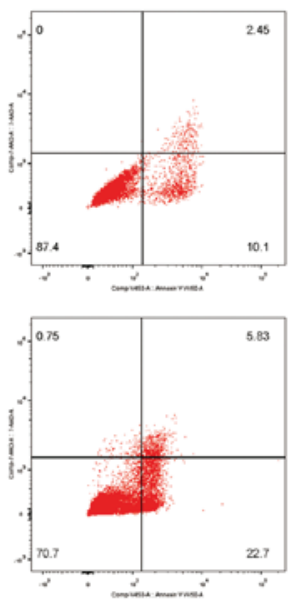

80

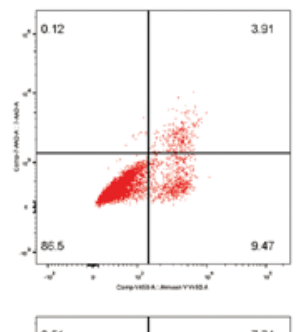

Annexin V-450

B

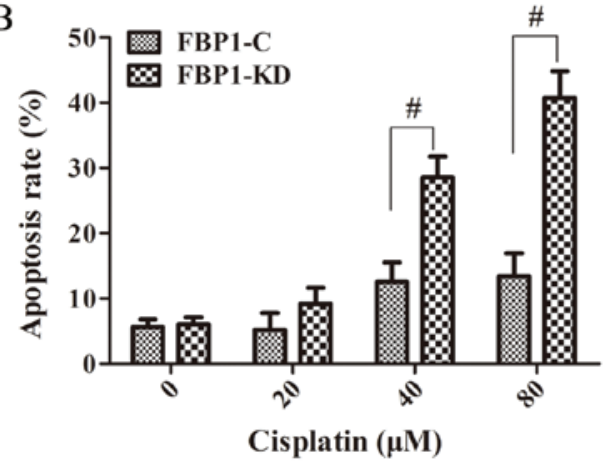

D

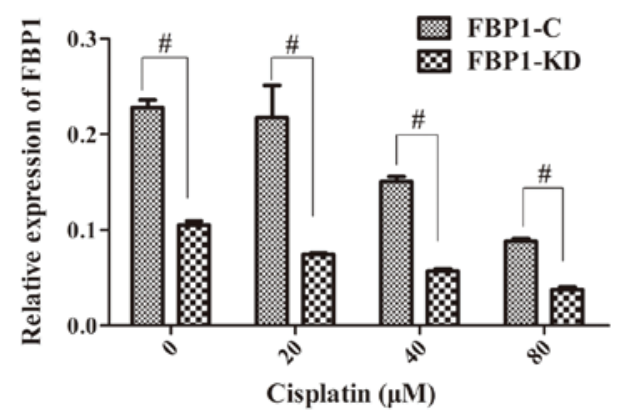

$\mathrm{C}$
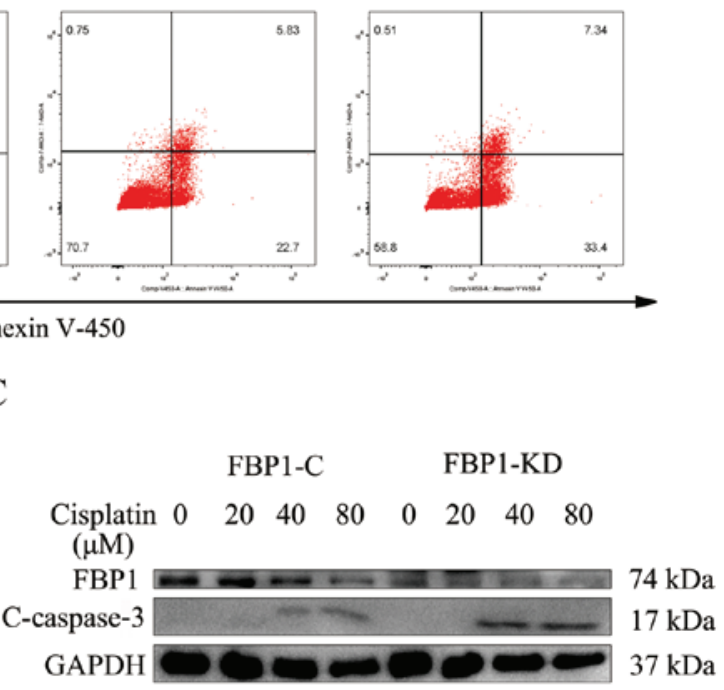

$\mathrm{E}$

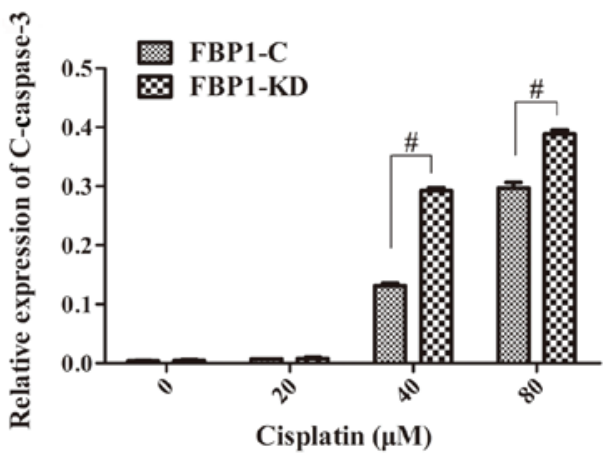

Figure 6. Knockdown of FBP1 increases apoptosis induced by cisplatin treatment. (A and B) Apoptotic FBP1-C and FBP1-KD MDA-MB-231 cells were detected by (A) Annexin-V450/7-AAD assay after treated with cisplatin for $48 \mathrm{~h}$ at the indicated concentrations and (B) apoptotic rates are presented. (C) expression of FBP1 and C-Caspase-3 detected in FBP1-C and FBP1-KD MDA-MB-231cells by western blot analysis following treatment with cisplatin for $48 \mathrm{~h}$ at the indicated concentrations. (D and E) relative expression of (D) FBP1 and (E) C-Caspase-3 against GADPH examined by densitometry. The data are the means \pm SD of 3 independent experiments. "P<0.01. FBP1-C, FBP1 control; FBP1-KD, FBP1 knockdown; FBP1, far upstream element binding protein 1; C-Caspase-3, cleaved caspase-3.

cooperate to either induce or repress gene expression including E2F1 $(31,32)$. As regards the mechanisms underlying the regulatory effects of FBP1 on MMP-2, further investigations are warranted to determine this in the future.

Cisplatin is a commonly used chemotherapeutic drug in patients with TNBC. A recent study on patients with refractory breast cancer demonstrated that tumor profiling based therapy resulted in a survival benefit (33). Therefore, enhancing our understanding of the mechanisms implicated in cisplatin treatment may improve the management of TNBC. The present study demonstrated that cisplatin reduced FBP1 expression in cisplatin-treated advanced TNBC cells, and FBP1 knockdown enhanced the sensitivity of TNBC cells to cisplatin. Cisplatin treatment upregulated the expression of C-Caspase-3 in the FBP1-KD cells to a greater extent than in the FBP1-C cells. This indicated that cisplatin treatment induced more prominent apoptosis in the FBP1-KD cells compared with the FBP1-C cells. The inhibition on FBP1 expression may be one of the reasons that cisplatin abrogates breast cancer development. However, the high expression of FBP1 in cancer cells/tissues inhibits cancer cell apoptosis resulting from cisplatin treatment. There may be a negative feedback loop between FBP1 expression and the therapeutic efficacy of cisplatin in tumors. The mechanisms through 
which cisplatin regulates FBP1 warrant further clarification in the future.

The clinical treatment of TNBC remains challenging due to the lack of available targets. Chemotherapy has significantly improved from previously administered treatments. In the present study, the progression of breast cancer was demonstrated to be positively associated with FBP1 expression. FBP1 knockdown inhibited cell viability, cell cycle transition and cell migration, and increased the sensitivity of TNBC cells to cisplatin. As a highly expressed protein in breast cancer tissues, FBP1 promotes cell proliferation and cell migration, and neutralizes the sensitivity of TNBC cells to cisplatin, but has no effect on apoptosis. Based on the above-mentioned facts, FBP1 may be a potential adjuvant drug target rather than a potential chemotherapeutic target for breast cancer treatment. In the future, the authors aim to perform further studies on the synergistic effects between FBP1 and radiation, chemicals, etc.

In conclusion, FBP1 is a potential adjuvant drug target for breast cancer treatment and the downregulation of FBP1 may be a potential strategy for the development of novel TNBC treatments.

\section{Acknowledgements}

The authors would like to thank Dr Siyu Liu from Rutgers, the State University of New Jersey, USA for her assisting in the writing of the manuscript. Flow cytometric analysis was performed with the assistance of Guangdong Provincial Key Laboratory of Malignant Tumor Epigenetics and Gene Regulation, Sun Yat-Sen Memorial Hospital, Sun Yat-Sen University.

\section{Funding}

The present study was supported by the National Natural Science Foundation of China (grant nos. 81272222 to ZL and 81902802 to XX), the Guangdong Provincial Natural Science Foundation of China (grant no. 2016A030313425 to ZZ), the Medical Science and Technology Research Foundation of Guangdong (grant nos. B2016018 to XX and A2018063 to $\mathrm{XX}$ ), the research grants of Guangdong Bureau of Traditional Chinese Medicine (nos. 20181206 to ZL and 20191260 to XX), the Medical and Health Science and Technology Project of Guangzhou (grant no. 20191A011016 to WL), the research grants of Guangzhou Municipal Health and Family Planning Commission (nos. 20161A010019 to XX and 20181A010017 to $\mathrm{XX)}$.

\section{Availability of data and materials}

All data generated or analyzed during this study are included in this published article or are available from the corresponding author on reasonable request.

\section{Authors' contributions}

WL, XX, ZL, XL and ZZ were involved in the initial experimental design. WL, WC and XH prepared the tissue samples. $\mathrm{XX}$ and WL performed the experiments. WL and XX wrote the manuscript. ZL and $\mathrm{ZZ}$ analyzed the data and wrote the manuscript. All authors have read and approved the final manuscript.

\section{Ethics approval and consent to participate}

Informed consents for the use of their samples in scientific research were obtained from all patients. The present study was conducted after the protocol was approved by the Medical Ethics Committee of Guangzhou Red Cross Hospital of Jinan University (approval no. 2015-045-01).

\section{Patient consent for publication}

Not applicable.

\section{Competing interests}

The authors declared that they have no competing interests.

\section{References}

1. Tobin NP, Harrell JC, Lövrot J, Egyhazi Brage S, Frostvik Stolt M, Carlsson L, Einbeigi Z, Linderholm B, Loman N, Malmberg M, et al; TEX Trialists Group: Molecular subtype and tumor characteristics of breast cancer metastases as assessed by gene expression significantly influence patient post-relapse survival. Ann Oncol 26: 81-88, 2015.

2. Omarini C, Guaitoli G, Pipitone S, Moscetti L, Cortesi L, Cascinu S and Piacentini F: Neoadjuvant treatments in triple-negative breast cancer patients: Where we are now and where we are going. Cancer Manag Res 10: 91-103, 2018.

3. Hurvitz S and Mead M: Triple-negative breast cancer: Advancements in characterization and treatment approach. Curr Opin Obstet Gynecol 28: 59-69, 2016.

4. Chalakur-Ramireddy NKR and Pakala SB: Combined drug therapeutic strategies for the effective treatment of Triple Negative Breast Cancer. Biosci Rep 38: 38, 2018.

5. Pénzváltó Z, Lánczky A, Lénárt J, Meggyesházi N, Krenács T, Szoboszlai N, Denkert C, Pete I and Győrffy B: MEK1 is associated with carboplatin resistance and is a prognostic biomarker in epithelial ovarian cancer. BMC Cancer 14: 837, 2014.

6. Loibl S, O'Shaughnessy J, Untch M, Sikov WM, Rugo HS, McKee MD, Huober J, Golshan M, von Minckwitz G, Maag D, et al: Addition of the PARP inhibitor veliparib plus carboplatin or carboplatin alone to standard neoadjuvant chemotherapy in triple-negative breast cancer (BrighTNess): A randomised, phase 3 trial. Lancet Oncol 19: 497-509, 2018.

7. von Minckwitz G, Schneeweiss A, Loibl S, Salat C, Denkert C, Rezai M, Blohmer JU, Jackisch C, Paepke S, Gerber B, et al: Neoadjuvant carboplatin in patients with triple-negative and HER2-positive early breast cancer (GeparSixto; GBG 66): A randomised phase 2 trial. Lancet Oncol 15: 747-756, 2014.

8. Poggio F, Bruzzone M, Ceppi M, Pondé NF, La Valle G, Del Mastro L, de Azambuja E and Lambertini M: Platinum-based neoadjuvant chemotherapy in triple-negative breast cancer: A systematic review and meta-analysis. Ann Oncol 29: 1497-1508, 2018.

9. Tutt A, Tovey H, Cheang MCU, Kernaghan S, Kilburn L, Gazinska P, Owen J, Abraham J, Barrett S, Barrett-Lee P, et al: Carboplatin in BRCA1/2-mutated and triple-negative breast cancer BRCAness subgroups: The TNT Trial. Nat Med 24: 628-637, 2018.

10. Ahmad S: Platinum-DNA interactions and subsequent cellular processes controlling sensitivity to anticancer platinum complexes. Chem Biodivers 7: 543-566, 2010.

11. Kim H and D'Andrea AD: Regulation of DNA cross-link repair by the Fanconi anemia/BRCA pathway. Genes Dev 26: 1393-1408, 2012.

12. Debaize L and Troadec MB: The master regulator FUBP1: Its emerging role in normal cell function and malignant development. Cell Mol Life Sci 76: 259-281, 2019. 
13. Steiner M, Schneider L, Yillah J, Gerlach K, Kuvardina ON Meyer A, Maring A, Bonig H, Seifried E, Zörnig M, et al: FUSE binding protein 1 (FUBP1) expression is upregulated by T-cell acute lymphocytic leukemia protein 1 (TAL1) and required for efficient erythroid differentiation. PLoS One 14: e0210515, 2019.

14. Malz M, Bovet M, Samarin J, Rabenhorst U, Sticht C, Bissinger M, Roessler S, Bermejo JL, Renner M, Calvisi DF, et al: Overexpression of far upstream element (FUSE) binding protein (FBP)-interacting repressor (FIR) supports growth of hepatocellular carcinoma. Hepatology 60: 1241-1250, 2014.

15. Venturutti L, Cordo Russo RI, Rivas MA, Mercogliano MF, Izzo F, Oakley RH, Pereyra MG, De Martino M, Proietti CJ Yankilevich P, et al: MiR-16 mediates trastuzumab and lapatinib response in ErbB-2-positive breast and gastric cancer via its novel targets CCNJ and FUBP1. Oncogene 35: 6189-6202, 2016

16. Liu ZH, Hu JL, Liang JZ, Zhou AJ, Li MZ, Yan SM, Zhang X, Gao S, Chen L, Zhong Q, et al: Far upstream element-binding protein 1 is a prognostic biomarker and promotes nasopharyngeal carcinoma progression. Cell Death Dis 6: e1920, 2015.

17. Zhang $\mathrm{J}$ and Chen QM: Far upstream element binding protein 1: A commander of transcription, translation and beyond. Oncogene 32: 2907-2916, 2013

18. Livak KJ and Schmittgen TD: Analysis of relative gene expression data using real-time quantitative PCR and the 2(-Delta Delta C(T)) Method. Methods 25: 402-408, 2001.

19. Duncan R, Bazar L, Michelotti G, Tomonaga T, Krutzsch H, Avigan M and Levens D: A sequence-specific, single-strand binding protein activates the far upstream element of c-myc and defines a new DNA-binding motif. Genes Dev 8: 465-480, 1994.

20. Rodríguez D, Morrison CJ and Overall CM: Matrix metalloproteinases: What do they not do? New substrates and biological roles identified by murine models and proteomics. Biochim Biophys Acta 1803: 39-54, 2010.

21. Siegel RL, Miller KD and Jemal A: Cancer statistics, 2016. CA Cancer J Clin 66: 7-30, 2016.

22. Jia Y, Chen Y, Wang Q, Jayasinghe U, Luo X, Wei Q, Wang J, Xiong $\mathrm{H}$, Chen $\mathrm{C}, \mathrm{Xu} \mathrm{B}$, et al: Exosome: Emerging biomarker in breast cancer. Oncotarget 8: 41717-41733, 2017.

23. Yang L, Zhu JY, Zhang JG, Bao BJ, Guan CQ, Yang XJ, Liu YH, Huang YJ, Ni RZ and Ji LL: Far upstream element-binding protein 1 (FUBP1) is a potential c-Myc regulator in esophageal squamous cell carcinoma (ESCC) and its expression promotes ESCC progression. Tumour Biol 37: 4115-4126, 2016.
24. Ding Z, Liu X, Liu Y, Zhang J, Huang X, Yang X, Yao L, Cui G and Wang D: Expression of far upstream element (FUSE) binding protein 1 in human glioma is correlated with c-Myc and cell proliferation. Mol Carcinog 54: 405-415, 2015.

25. Xiong X, Zhang J, Hua X, Cao W, Qin S, Dai L, Liu W, Zhang Z, Li X and Liu Z: FBP1 promotes ovarian cancer development through the acceleration of cell cycle transition and metastasis. Oncol Lett 16: 1682-1688, 2018.

26. Talmadge JE and Fidler IJ: AACR centennial series: the biology of cancer metastasis: historical perspective. Cancer Res 70 5649-5669, 2010

27. Massagué $\mathbf{J}$ and Obenauf AC: Metastatic colonization by circulating tumour cells. Nature 529: 298-306, 2016.

28. Butler GS and Overall CM: Updated biological roles for matrix metalloproteinases and new 'intracellular' substrates revealed by degradomics. Biochemistry 48: 10830-10845, 2009.

29. Zitka O, Kukacka J, Krizkova S, Huska D, Adam V, Masarik M, Prusa R and Kizek R: Matrix metalloproteinases. Curr Med Chem 17: 3751-3768, 2010.

30. Kessenbrock K, Plaks V and Werb Z: Matrix metalloproteinases: Regulators of the tumor microenvironment. Cell 141: 52-67, 2010

31. Vincenti MP and Brinckerhoff CE: Signal transduction and cell-type specific regulation of matrix metalloproteinase gene expression: Can MMPs be good for you? J Cell Physiol 213 355-364, 2007

32. Li Z, Guo Y, Jiang H, Zhang T, Jin C, Young CY and Yuan H: Differential regulation of MMPs by E2F1, Sp1 and NF-kappa B controls the small cell lung cancer invasive phenotype. BMC Cancer 14: 276, 2014.

33. Jameson GS, Petricoin EF, Sachdev J, Liotta LA, Loesch DM, Anthony SP, Chadha MK, Wulfkuhle JD, Gallagher RI, Reeder KA, et al: A pilot study utilizing multi-omic molecular profiling to find potential targets and select individualized treatments for patients with previously treated metastatic breast cancer. Breast Cancer Res Treat 147: 579-588, 2014.

This work is licensed under a Creative Commons Attribution-NonCommercial-NoDerivatives 4.0 International (CC BY-NC-ND 4.0) License. 